\title{
Core Temperature Measurement-Principles of Correct Measurement, Problems, and Complications
}

\author{
Hubert Hymczak ${ }^{1,2, \dagger}$, Aleksandra Gołąb ${ }^{3,+}+\mathbb{D}$, Konrad Mendrala ${ }^{4}\left(\mathbb{D}\right.$, Dariusz Plicner ${ }^{2,5, *(\mathbb{D})}$, Tomasz Darocha ${ }^{4}$, \\ Paweł Podsiadło ${ }^{6}$ (D), Damian Hudziak ${ }^{7}\left(\mathbb{D}\right.$, Radosław Gocoł ${ }^{7}$ and Sylweriusz Kosiński ${ }^{8}(\mathbb{D}$ \\ 1 Department of Anesthesiology and Intensive Care, John Paul II Hospital, 31-202 Krakow, Poland; \\ hymczak@op.pl \\ 2 Faculty of Medicine and Health Sciences, Andrzej Frycz Modrzewski Krakow University, \\ 30-705 Krakow, Poland \\ 3 Faculty of Medicine and Dentistry, Pomeranian Medical University, 70-204 Szczecin, Poland; \\ olagoab13@gmail.com \\ 4 Department of Anaesthesiology and Intensive Care, Medical University of Silesia, 40-055 Katowice, Poland; \\ k.mendrala@gmail.com (K.M.); tomekdarocha@wp.pl (T.D.) \\ 5 Department of Cardiovascular Surgery and Transplantation, John Paul II Hospital, 31-202 Krakow, Poland \\ 6 Institute of Medical Sciences, Jan Kochanowski University, 25-369 Kielce, Poland; p.podsiadlo.01@gmail.com \\ 7 Department of Cardiac Surgery, Upper-Silesian Heart Center, 40-055 Katowice, Poland; \\ damhud@gmail.com (D.H.); gocot@poczta.onet.pl (R.G.) \\ 8 Faculty of Health Sciences, Jagiellonian University Medical College, 31-008 Krakow, Poland; kosa@mp.pl \\ * Correspondence: plicner.dariusz@gmail.com \\ + Authors have equal contribution to this work.
}

Citation: Hymczak, H.; Gołąb, A.; Mendrala, K.; Plicner, D.; Darocha, T.; Podsiadło, P.; Hudziak, D.; Gocoł, R.; Kosiński, S. Core Temperature Measurement-Principles of Correct Measurement, Problems, and Complications. Int. J. Environ. Res. Public Health 2021, 18, 10606. https:// doi.org/10.3390/ijerph182010606

Academic Editor: Paul B. Tchounwou

Received: 4 September 2021

Accepted: 7 October 2021

Published: 10 October 2021

Publisher's Note: MDPI stays neutral with regard to jurisdictional claims in published maps and institutional affiliations.

Copyright: (c) 2021 by the authors. Licensee MDPI, Basel, Switzerland. This article is an open access article distributed under the terms and conditions of the Creative Commons Attribution (CC BY) license (https:/ / creativecommons.org/licenses/by/ $4.0 /)$.

\begin{abstract}
Core temperature reflects the temperature of the internal organs. Proper temperature measurement is essential to diagnose and treat temperature impairment in patients. However, an accurate approach has yet to be established. Depending on the method used, the obtained values may vary and differ from the actual core temperature. There is an ongoing debate regarding the most appropriate anatomical site for core temperature measurement. Although the measurement of body core temperature through a pulmonary artery catheter is commonly cited as the gold standard, the esophageal temperature measurement appears to be a reasonable and functional alternative in the clinical setting. This article provides an integrative review of invasive and noninvasive body temperature measurements and their relations to core temperature.
\end{abstract}

Keywords: thermoregulation; core temperature; measurement

\section{Introduction}

Thermoregulation is the element of homeostasis that maintains a stable internal temperature, regardless of the environmental conditions. Central thermoregulatory management is based on afferent thermal signals coming from the core and peripheral thermoreceptors, which are integrated by the central nervous system, especially the hypothalamus. Currently, the traditional model of an individual set point in the hypothalamus is being questioned. There is increasing evidence that body temperature is controlled by independent thermoeffector loops composed of specific afferent and efferent branches collectively producing a balance point of core temperature $\left(\mathrm{T}_{\mathrm{c}}\right)$ [1,2]. It is also believed that mean body temperature characterizes the overall thermal status, but its use is impractical for everyday use [3].

The core thermal compartment is very well perfused and relatively homogeneous. The $\mathrm{T}_{\mathrm{C}}$ of the human body is maintained within a narrow range, close to $37 \pm 0.5^{\circ} \mathrm{C}$ at rest. Among healthy persons, the average daily temperature can differ by $0.5^{\circ} \mathrm{C}$. The menstrual cycle is also one of the main causes of temperature variations. In addition, daily variations can be as much as $0.25-0.5{ }^{\circ} \mathrm{C}$, with the lowest body temperature occurring usually at 
about 4 a.m. and the highest about 6 p.m. [4]. Temperatures of the peripheral parts of the body are cooler than the core, depending on the environment and thermoregulatory vasoconstriction. Thus, the temperature that best describes a human thermal status is the $\mathrm{T}_{\mathrm{c}}$. In the present review, we discuss the current insights into proper body temperature measurements as well as related challenges and complications.

\section{Mechanisms of Thermoregulation}

The $T_{c}$ is a balance between heat generated by the body and heat lost to the environment. Humans are warm-blooded animals; therefore, our bodies are able to adjust their metabolic rate to maintain equal heat production and loss. This statement is important because proper body function depends on a stable $\mathrm{T}_{\mathrm{c}}$. Body heat production is mainly the effect of a transformation of chemical energy in foods into heat by cellular oxidative metabolism $[5,6]$.

Skin is the largest structure of the human body and is responsible for about $90 \%$ of heat loss. Heat loss rate is determined by the level of heat transferred from inner tissues to the skin and from the skin to the surrounding environment by four mechanisms: radiation, evaporation, convection, and conduction.

Radiation is the electromagnetic energy radiated by the body in the form of electromagnetic waves (mainly infrared rays) and is similar to the process of heat leaving a woodstove. Radiation is the most important mechanism of heat loss, accounting for approximately $65 \%$ of loss. This normal process usually occurs in air temperatures below $20{ }^{\circ} \mathrm{C}$. Evaporation is an endothermic process that converts liquid into gas and is the second major source of heat loss, accounting for about $20 \%$. Water vaporization needs energy and consumes heat, therefore accelerating heat loss. Evaporation is the basic mechanism of heat loss in high ambient temperatures. During intense exercise, the body loses $85 \%$ of its heat through sweating. Convection is heat loss by the physical movement of a fluid or gas from one location to another. This mechanism of heat loss is similar to sitting in front of a fan. The body loses $10 \%$ to $15 \%$ of its heat through convection. Conduction is the loss of molecular kinetic energy and occurs when heat is transferred between two objects that are in contact with one another, such as heat loss that occurs from sleeping on cold ground. The body loses about $2 \%$ of its heat through air conduction, although different mediums transfer heat by conduction at different rates. For instance, the conductive transfer of water is 100 times that of air, so heat can be lost from the body very quickly when it is immersed in cold water [5-7].

To maintain a normal $\mathrm{T}_{\mathrm{c}}$, the hypothalamus works by a variety of autonomic mechanisms, such as changing basal metabolism, muscle tone, thyroid activity, or adrenal response. There is also a hypothalamic efferent component that includes the proper adjustment of sympathetic stimulation to subcutaneous vessels, thus inducing the vasoconstriction or vasodilation of peripheral vessels where heat loss is at its highest. Thermoregulatory functions can generally be divided into autonomic and behavioral reactions.

The primary autonomic thermoregulatory defenses are active precapillary vasodilation, arteriovenous shunt vasoconstriction, and shivering in cold exposure. Sweating (and consequent evaporation) is the only method of cooling down in a hot environment when the external temperature exceeds the temperature of the body. Sweating starts immediately after the onset of exercise, which is most likely due to various central mechanisms, including the baroreceptor reflex [8]. With heat acclimatization, sweat volume can be as high as $2-31 / \mathrm{h}$, mainly due to lowering the temperature threshold for sweating and the redistribution of sweat secretion more peripherally [9].

In a cold environment, thermoregulatory vasoconstriction is mainly limited to arteriovenous shunts in the limbs. Although anatomically limited to toes and fingers, this mechanism can influence the blood flow to whole extremities and is efficient at cooling the body's temperature when open and restricting metabolic heat when closed [3]. Shivering can quickly enhance the metabolic rate and continue to do so for up to $6 \mathrm{~h}$ [10]. Non- 
shivering thermogenesis, i.e., the activation of brown fat, can be used in infants and, in a small proportion, also in a certain adult population [11].

Other changes include an efferent behavioral component that is the most effective reaction to fluctuations in body temperature. Behavioral modifications initiated by excessive heat loss include adding more clothing, seeking shelter, curling up to decrease the proportion of exposed body surface area, exercising, or starting a fire to enhance heat gain via radiation. If the body is overheated, a common behavioral response would be to remove some outer clothing, minimize physical activity, or increase cooling by convection, such as standing in front of a fan $[5,6]$.

To maintain the above mechanisms in hemostasis, the organism needs an appropriate cardiovascular function and intravascular volume, as the organism must be able to transfer the increasing internal temperature to its surface for release. Older persons are at increased risk for disturbances of thermoregulation as a result of reduced cardiac function and decreased intravascular volume. Behavioral reactions can be impaired in the elderly, especially for those with coexisting dementia, whereas, in newborns, numerous characteristics of their physiology contribute to the enhanced risk of heat loss. The large surface-area-to-body-mass ratio promotes cooling through conduction. Furthermore, newborns have a lesser amount of subcutaneous fat to provide insulation. In newborns, the blood flow is additionally modified, causing peripheral cyanosis. Finally, newborns lack the shivering mechanism and have to depend on non-shivering thermogenesis [12].

An abnormality in muscular function, reduced metabolism, or prolonged exposure to low ambient temperatures could result in hypothermia. At a body temperature below $33{ }^{\circ} \mathrm{C}$, oxygen consumption decreases and enzyme activity reduces, whereas extended exposure to elevated temperatures, failure to disperse excessive body heat, or an increase in heat production (for example, enhanced metabolism or muscular work) may result in hyperthermia. During hyperthermia, the rate of reaction will diminish due to the denaturing of proteins, resulting in impaired cellular function $[6,13]$.

\section{Core Temperature Measurements}

The precision of temperature monitoring depends on the measurement site and the measurement system. Four monitoring sites are considered to be $T_{c}$ sites: the tympanic membrane, nasopharynx, esophagus, and pulmonary artery [3]. In clinical practice, these measurement locations are most preferable [3,14].

\subsection{Body Surface}

Due to poor peripheral circulation, the measurements do not accurately reflect the $T_{c}$ but reflect only the temperature of the skin. Body surface measurement is performed using a thermistor that is applied to the surface of the skin or using an infrared thermometer. Numerous studies have demonstrated that the measurement of skin temperature using thermophototropic liquid crystals, typically used for forehead application devices, is imprecise and often shows a normal temperature despite an elevated $T_{c}[6,13]$.

\subsection{Oral}

This is the most widespread technique for assessing body temperature. However, oral temperature is an unreliable method for the measurement of $T_{c}$ because it is affected by environmental factors and bias caused by such factors as smoking or hot or cold beverages being consumed prior to the measurement. Lastly, mouth-to-mouth cross-infection or oral mucosa laceration may appear. Additionally, there are differences in the measurements recorded from the different sites in the mouth cavity, depending on the exact location of where the bulb of the thermometer is positioned. The preferred place for oral temperature measurement is the sublingual pocket $[6,13,15]$. 


\subsection{Axilla}

Measuring temperature in the axilla is less precise in comparison with the other noninvasive sites, and the temperature reading is usually much lower than the $\mathrm{T}_{\mathrm{c}}$. Although it is safe, easily accessible, and a comfortable method of temperature measurement, there are numerous disadvantages. Axilla temperature measurement needs supervision in case the dislocation of the thermometer occurs, and this method is more time consuming than in other measurement sites. In addition, the measurement could be affected by ambient temperature, sweating, and evaporation. Therefore, this method of temperature measurement is not a suitable method to use in clinical settings $[6,13]$.

\subsection{Tympanic Membrane}

This technique is quick and simple to use. Performed correctly, the reading is only slightly affected by environmental temperature. Moreover, it is safer than oral or rectal thermometers, especially for children. However, as the tympanic membrane receives blood from the branches of the internal carotid artery that supplies blood to the hypothalamus, this method of temperature measurement is problematic and an unreliable reflection of the $T_{c}$. Being in direct contact with the environment, measurements at this location may be influenced by a lack of complete isolation from the outside temperature, obstruction or contamination of the auditory canal, or the presence of snow in the auditory canal. Moreover, in certain clinical conditions, such as cardiac arrest and reduced blood flow through the ICA, the tympanic membrane is not sufficiently perfused, and, therefore, temperature measurements can be inaccurate $[13,16-18]$.

\subsection{Rectum}

Rectal temperature is in poor correlation with $\mathrm{T}_{\mathrm{c}}$, and the readings can be significantly delayed [19]. Clinically, the rectal temperature is the most widely used, particularly in children. The rectal probe must be introduced to a depth of $\geq 15 \mathrm{~cm}$ so that the temperature sensors can be positioned near the large arteries of the pelvic region. Usually, temperature readings in the rectum are higher than those determined in other parts of the body. Moreover, in circulation instability, rectal temperature will be lower than the real $\mathrm{T}_{\mathrm{c}}$. This kind of measurement is a reliable method only in conditions closely related to normothermia, but there is a considerable delay in rectal temperature results, particularly during rapid temperature changes. Moreover, rectal inflammation can influence temperature readings, and hard feces can impede the placement of the probe. Additionally, rectal temperature can be incorrectly higher if warmed peritoneal lavage is performed in patients with hypothermia. The insertion of the rectal probe can cause considerable pain and discomfort, especially for patients with perirectal infection. Conscious patients may experience a feeling of rectal fullness and the desire to defecate during insertion of the thermistor into the rectum. Moreover, rectal insertion is often terrifying and can be psychologically harmful for children. The risk of rectal perforation is another limitation of this method, especially for unconscious patients in whom distension and the thinning of the rectal wall develops due to the temporary paralysis of the autonomic nervous system [16].

\subsection{Urinary Bladder}

Kidneys receive about $25 \%$ of the cardiac output; therefore, if the urine flow rate is within a normal range, the urinary bladder temperature would closely match the $T_{c}$. Since urine output is usually monitored in hospitalized patients, a simultaneous urinary bladder temperature measurement is very useful and is becoming increasingly common for use in intensive care unit patients. Temperature-sensing indwelling urinary catheters allow for the continuous drainage of urine and the constant measurement of body temperature.

Due to the closeness of the urinary bladder to the rectum, the values of bladder temperature have characteristics very comparable to those of rectal temperature. Similar to the rectum temperature measurement, this technique is a reliable approach, but only in situations when body temperature is near to normothermia, whereas bladder temperature 
responds to $T_{c}$ changes faster than rectal and skin temperature changes but slower than esophageal temperatures. A better correlation with $\mathrm{T}_{\mathrm{c}}$ has been noted in the occurrence of high urinary volumes. Reduced urine production due to a decreased cardiac output or hypothermia causes this method of temperature measurement to be inaccurate. Similar to rectal temperature, bladder temperature can also be incorrectly higher if warmed peritoneal lavage is performed in patients with hypothermia. The problems and complications of this method of temperature measurement are the same as those that arise during bladder catheterization, of which catheter-associated urinary tract infection is the most common. Urethral injury, catheter obstruction, and urine leakage are other possible complication $[5,16,20]$.

\subsection{Nasopharynx}

The nasopharynx is one of the most reliable locations for the measurement of $T_{c}$. Additionally, the insertion of the probe into the nasopharynx is quite simply achieved and is a safe procedure. Therefore, the nasopharynx is a frequently used temperature monitoring location during surgical procedures. The optimal site for nasopharyngeal temperature measurement is near the internal carotid artery. The nearest part of the nasopharyngeal mucosa to the internal carotid artery is within the upper- or mid-nasopharynx. The nasopharyngeal probe should be inserted through the middle or inferior meatus in the nasal cavity. Any nasopharyngeal temperature probe insertion depth between 10 and $20 \mathrm{~cm}$ corresponds well to the $T_{c}$ in adults [21-23]. Similar to tympanic membrane temperature measurement, this technique may give false low values in patients with unstable circulation and can lead to errors in the temperature measurements as a result of imprecise probe location or obstructed nasal canals.

\subsection{Esophagus}

The esophagus is the preferred location to determine $T_{c}$ because of its location near the left atrium and left ventricle. Esophageal temperature strongly associates with pulmonary artery temperature and is a basic method of temperature measurement for intubated patients. The determination of esophageal temperature is also favored because of its quick reaction to changes in $T_{c}[17,20,24]$.

Esophageal temperature measurement should reveal the temperature of the myocardium and, therefore, the probe must be perfectly placed at the level of the heart. The esophageal probe must be inserted in the lower third of the esophagus, and a lateral chest X-ray needs to be taken for an evaluation of the insertion length of the probe. An assessment of chest X-rays demonstrates that, at the level of the T8 and T9, the probe is under the tracheal bifurcation and close to the heart. Several non-radiographic methods of assessing the position of the esophageal probe have also been proposed. These methods are usually based on the height of the patient $[13,16,17,19]$. The following equations were developed to calculate the distance from the nasal flare to the point between $\mathrm{T} 8$ and T9, based (L) on the patient's height: $\mathrm{L}(\mathrm{cm})=0.228 \times$ standing height -0.194 , or more simply, $\mathrm{L}(\mathrm{cm})=$ standing height $/ 5+5 \mathrm{~cm}[25]$.

Although esophageal probe insertion is usually considered to be a safe method, there is the possibility of some complications. Major complications are rare and include esophageal bleeding, perforation, and arrhythmias. Temperature measurements taken with the use of a proximally positioned probe can be incorrectly elevated owing to ventilation with warmed gases. Furthermore, fluids passing through the nasogastric tubes can also change the temperature indication. Malposition of the esophageal probe can cause inaccurate $T_{c}$ readings and cause bronchospasm and hypoxemia due to tracheal misplacement.

\subsection{Pulmonary Artery}

The use of the pulmonary artery catheter is limited to a specific group of patients, mainly critical care and cardiac surgery patients, to monitor hemodynamic parameters, such as cardiac output, pulmonary artery wedge pressure, and vascular resistance. Ad- 
ditionally, it is possible to measure blood temperature with a thermistor placed on the distal port in the pulmonary artery. $T_{C}$ measurement with the pulmonary artery catheter is the most precise technique in clinical settings because the pulmonary artery carries blood directly from the body's core; however, this technique is too invasive for routine use [24,26].

A study comparing pulmonary artery temperature measurement to other methods showed that infrared ear thermometers offered a comparatively close assessment of pulmonary artery $\mathrm{T}_{\mathcal{C}}$, but with more changeability than oral or urinary bladder techniques, whereas axillary measurements were significantly lower than the pulmonary artery temperature and extremely variable [27]. The insertion of a Swan-Ganz catheter, which is used for pulmonary artery temperature measurement, can lead to several complications, including pneumothorax, cardiac arrhythmias, pulmonary infarction, and infection [28].

\section{Conclusions}

A reference technique for $T_{c}$ measurement is the pulmonary artery temperature reading. In clinical settings, the temperature readings obtained from the esophagus are considered to be a gold standard, whereas tympanic measurement using the thermistor technique is a reliable option and is a suitable alternative if invasive methods of $T_{c}$ measurement are impossible to achieve (Table A1) [26,29].

Ideally, the temperature measurement should accurately reflect the $T_{c}$ in all age groups, be easy, non-invasive, harmless, and technique independent. Lastly, it should indicate the $T_{c}$ as accurately as possible without being markedly influenced by the ambient temperature. Although we are in an era of continuing implementation of sophisticated medical technology, no standard techniques are currently being developed to determine body temperature. Twenty years ago, Moran and Mendal stated that, during this amazing era, we "forgot" to develop a better method for measuring body temperature $[18,27]$. This statement is still valid, and today we can also state that it is surprising that such an instrument has not yet been created. The key is selecting an appropriate monitoring site depending on clinical circumstances.

Author Contributions: H.H. and A.G.: article concept and design, literature analysis, and article writing; K.M., D.P., T.D., P.P., D.H. and R.G.: literature analysis and manuscript writing; S.K. and T.D.: article review and editing; S.K.: article writing, review, and editing. All authors have read and agreed to the published version of the manuscript.

Funding: This research received no external funding.

Institutional Review Board Statement: Not applicable.

Informed Consent Statement: Not applicable.

Data Availability Statement: Not applicable.

Conflicts of Interest: The authors declare no conflict of interest.

Appendix A

Table A1. Summary of temperature measurements.

\begin{tabular}{ccccc}
\hline Measurement location & Accuracy & Special Requirements & Advantages & Disadvantages \\
\hline Body surface & Poor & None & $\begin{array}{c}\text { Easy and widely available } \\
\text { (also in prehospital care) }\end{array}$ & Inaccurate \\
\hline Oral & Poor & None & $\begin{array}{c}\text { Easy and widely available } \\
\text { (also in prehospital care) }\end{array}$ & Inaccurate \\
Axilla & Poor & None & $\begin{array}{c}\text { Easy and widely available } \\
\text { (also in prehospital care) }\end{array}$ & Inaccurate \\
\hline
\end{tabular}


Table A1. Cont.

\begin{tabular}{|c|c|c|c|c|}
\hline Measurement location & Accuracy & Special Requirements & Advantages & Disadvantages \\
\hline Tympanic membrane & Good & $\begin{array}{l}\text { Special insulated } \\
\text { thermistor }\end{array}$ & $\begin{array}{c}\text { Precise, repeatable, and } \\
\text { brain core temperature (possible } \\
\text { application in neurosurgery and deep } \\
\text { hypothermia cardiac surgery) }\end{array}$ & $\begin{array}{l}\text { High risk of } \\
\text { measurement error }\end{array}$ \\
\hline Rectum & Good & Rectal probe & $\begin{array}{l}\text { Easy, widely available (also in } \\
\text { prehospital conditions), precise, and } \\
\text { repeatable }\end{array}$ & High latency \\
\hline Urinary Bladder & Good & Urinary catheter & Precise and repeatable & High latency \\
\hline Nasopharynx & Good & None & $\begin{array}{l}\text { Easy and widely available } \\
\text { (also in prehospital conditions) }\end{array}$ & $\begin{array}{l}\text { High risk of } \\
\text { measurement error }\end{array}$ \\
\hline Esophagus & Most precise & $\begin{array}{l}\text { Long esophageal } \\
\text { thermistor }\end{array}$ & $\begin{array}{l}\text { Easy, widely available (also in } \\
\text { prehospital conditions), and repeatable }\end{array}$ & High latency \\
\hline Pulmonary Artery & Most precise & Swan-Ganz catheter & Precise and repeatable & $\begin{array}{l}\text { Invasive and restricted } \\
\text { to intensive care units }\end{array}$ \\
\hline
\end{tabular}

\section{References}

1. Nakamura, K. Afferent pathways for autonomic and shivering thermoeffectors. Handb. Clin. Neurol. 2018, 156, $263-279$. [CrossRef] [PubMed]

2. Romanovsky, A.A. The thermoregulation system and how it works. Handb. Clin. Neurol. 2018, 156, 3-43. [CrossRef] [PubMed]

3. Sessler, D.I. Perioperative Thermoregulation and Heat Balance. Lancet Lond. Engl. 2016, 387, 2655-2664. [CrossRef]

4. Walker, H.K.; Hall, W.D.; Hurst, J.W. (Eds.) Clinical Methods: The History, Physical, and Laboratory Examinations, 3rd ed.; Butterworths: Boston, MA, USA, 1990; ISBN 978-0-409-90077-4.

5. Tansey, E.A.; Johnson, C.D. Recent advances in thermoregulation. Adv. Physiol. Educ. 2015, 39, 139-148. [CrossRef]

6. Koop, L.K.; Tadi, P. Physiology, Heat Loss. In StatPearls; StatPearls Publishing: Treasure Island, FL, USA, 2021.

7. Wang, L.; Yin, H.; Di, Y.; Liu, Y.; Liu, J. Human Local and Total Heat Losses in Different Temperature. Physiol. Behav. 2016, 157, 270-276. [CrossRef] [PubMed]

8. Baker, L.B. Physiology of sweat gland function: The roles of sweating and sweat composition in human health. Temperature 2019, 6, 211-259. [CrossRef]

9. Périard, J.D.; Eijsvogels, T.M.H.; Daanen, H.A.M. Exercise under heat stress: Thermoregulation, hydration, performance implications, and mitigation strategies. Physiol. Rev. 2021, 101, 1873-1979. [CrossRef] [PubMed]

10. Haman, F.; Blondin, D.P. Shivering thermogenesis in humans: Origin, contribution and metabolic requirement. Temperature 2017, 22, 217-222. [CrossRef]

11. Chondronikola, M.; Bartelt, A.; Vidal-Puig, A.; Virtanen, K.A. Brown Adipose Tissue: From Heat Production in Rodents to Metabolic Health in Humans. Front. Endocrinol. 2021, 12, 739065. [CrossRef]

12. Urisarri, A.; González-García, I.; Estévez-Salguero, Á.; Pata, M.P.; Milbank, E.; López, N.; Mandiá, N.; Grijota-Martinez, C.; Salgado, C.A.; Nogueiras, R.; et al. BMP8 and activated brown adipose tissue in human newborns. Nat. Commun. 2021, $12,5274$. [CrossRef]

13. Petrone, P.; Asensio, J.A.; Marini, C.P. Management of Accidental Hypothermia and Cold Injury. Curr. Probl. Surg. 2014, 51, 417-431. [CrossRef]

14. Masè, M.; Micarelli, A.; Falla, M.; Regli, I.B.; Strapazzon, G. Insight into the use of tympanic temperature during target temperature management in emergency and critical care: A scoping review. J. Intensive Care 2021, 9, 43. [CrossRef]

15. Langham, G.E.; Maheshwari, A.; Contrera, K.; You, J.; Mascha, E.; Sessler, D.I. Noninvasive Temperature Monitoring in Postanesthesia Care Units. Anesthesiology 2009, 111, 90-96. [CrossRef]

16. Duong, H.; Patel, G. Hypothermia. In StatPearls; StatPearls Publishing: Treasure Island, FL, USA, 2021.

17. Osilla, E.V.; Marsidi, J.L.; Sharma, S. Physiology, Temperature Regulation. In StatPearls; StatPearls Publishing: Treasure Island, FL, USA, 2021.

18. Moran, D.S.; Mendal, L. Core Temperature Measurement: Methods and Current Insights. Sports Med. 2002, 32, 879-885. [CrossRef] [PubMed]

19. Lefrant, J.-Y.; Muller, L.; de La Coussaye, J.E.; Benbabaali, M.; Lebris, C.; Zeitoun, N.; Mari, C.; Saïssi, G.; Ripart, J.; Eledjam, J.-J. Temperature Measurement in Intensive Care Patients: Comparison of Urinary Bladder, Oesophageal, Rectal, Axillary, and Inguinal Methods versus Pulmonary Artery Core Method. Intensive Care Med. 2003, 29, 414-418. [CrossRef] [PubMed]

20. Lim, C.L.; Byrne, C.; Lee, J.K. Human Thermoregulation and Measurement of Body Temperature in Exercise and Clinical Settings. Ann. Acad. Med. 2008, 37, 347-353.

21. Lee, J.; Lim, H.; Son, K.G.; Ko, S. Optimal nasopharyngeal temperature probe placement. Anesth. Analg. 2014, 11, 875-879. [CrossRef] [PubMed] 
22. Wang, M.; Singh, A.; Qureshi, H.; Leone, A.; Mascha, E.J.; Sessler, D.I. Optimal Depth for Nasopharyngeal Temperature Probe Positioning. Anesth. Analg. 2016, 122, 1434-1438. [CrossRef]

23. Lim, H.; Lee, J.H.; Son, K.K.; Han, Y.J.; Ko, S. A method for optimal depth of the nasopharyngeal temperature probe: The philtrum to tragus distance. Korean J. Anesthesiol. 2014, 66, 195-198. [CrossRef]

24. Paal, P.; Gordon, L.; Strapazzon, G.; Maeder, M.B.; Putzer, G.; Walpoth, B.; Wanscher, M.; Brown, D.; Holzer, M.; Broessner, G.; et al. Accidental Hypothermia-an Update: The Content of This Review Is Endorsed by the International Commission for Mountain Emergency Medicine (ICAR MEDCOM). Scand. J. Trauma Resusc. Emerg. Med. 2016, 24, 111. [CrossRef]

25. Mekjavic, I.B.; Rempel, M.E. Determination of Esophageal Probe Insertion Length Based on Standing and Sitting Height. J. Appl. Physiol. 1990, 69, 376-379. [CrossRef]

26. Uleberg, O.; Eidstuen, S.; Vangberg, G.; Skogvoll, E. Temperature Measurements in Trauma Patients: Is the Ear the Key to the Core? Scand. J. Trauma Resusc. Emerg. Med. 2015, 23, 101. [CrossRef] [PubMed]

27. Erickson, R.S.; Kirklin, S.K. Comparison of Ear-Based, Bladder, Oral, and Axillary Methods for Core Temperature Measurement. Crit. Care Med. 1993, 21, 1528-1534. [CrossRef] [PubMed]

28. Evans, D.C.; Doraiswamy, V.A.; Prosciak, M.P.; Silviera, M.; Seamon, M.J.; Funes, V.R.; Cipolla, J.; Wang, C.F.; Kavuturu, S.; Torigian, D.A.; et al. Complications Associated with Pulmonary Artery Catheters: A Comprehensive Clinical Review. Scand. J. Surg. 2009, 98, 199-208. [CrossRef] [PubMed]

29. Strapazzon, G.; Procter, E.; Paal, P.; Brugger, H. Pre-hospital core temperature measurement in accidental and therapeutic hypothermia. High Alt. Med. Biol. 2014, 15, 104-111. [CrossRef] 